\title{
A study on factors influencing online behavioral advertising avoidance (Oba): Special reference to Sri Lankan online advertising
}

\author{
Shanika Wijenayake ${ }^{a^{*}}$ and Imesha Ruwan Pathirana ${ }^{a}$
}

${ }^{a}$ Department of Marketing Management, University of Kelaniya, Sri Lanka

\begin{tabular}{l}
\hline C H R O N I C L E \\
\hline Article history: \\
Received: March 15, 2019 \\
Received in revised format: April \\
142019 \\
Accepted: April 20, 2019 \\
Available online: \\
April 20, 2019 \\
\hline Keywords: \\
Advertising \\
Online Behavioral Targeting \\
Ad Avoidance \\
Goal Impediment \\
Privacy Concern \\
Perceived Personalization \\
Negative Experience
\end{tabular}

\section{A B S T R A C T}

This paper aims to investigate the effect of goal impediment, privacy concern, perceived personalization on the online add avoidance behavior. This task is accomplished through the negative experience. The primary objective of the study is to identify the effects the said issues in Sri Lanka. The study is designed as a cross sectional study where the data was collected using a questionnaire and the sample size was 384 . Collected data was analyzed through structural equation method in AMOS 22. All the hypotheses were supported by data. Therefore, it was concluded that goal impediment, privacy concern, perceived personalization had significant impacts on negative experience and negative experience had a significant impact on the online add avoidance behavior.

C) 2019 by the authors; licensee Growing Science, Canada

\section{Introduction}

Modern business is dominated by the internet today, the effect of the internet and information technology in business is massive and there has been radical changes in businesses because of the huge growth in internet and technology usage. Changes in the global business arena is influencing the local businesses too. Studies show that there is a remarkable growth in internet usage in Sri Lanka too. According to a recent study, Sri Lankan internet penetration in 2016 was found to be $30 \%$ and there has been nearly 1.5 million subscriptions of million cellular mobile connections and over 300,000 broadband and dial-up internet connections. Further, total number of internet users is around 6.1 million (Colombo Digital Marketers, 2017). With this hype the usage of internet in local businesses has increased drastically. One such usage is the application of Online Behavioral Advertisements (OBA).

OBA is a kind of advertising which tracks individual online behavior in order to deliver advertising tailored to his/ her interests (Tene \& Polonetsky, 2012; Cheng et al., 2019; Chen et al., 2019) which means collection of data from a particular computer or device regarding Web viewing behaviors over

* Corresponding author.

E-mail address: shanikaw@kln.ac.lk (S. Wijenayake)

(C) 2019 by the authors; licensee Growing Science, Canada doi: $10.5267 /$ j.msl.2019.4.014 
time and across nonaffiliated Web sites for the purpose of using such data to predict user preferences or interests to deliver advertising to that computer or device based on the preferences or interests (Kaushik \& Amrutlal, 2014). Intensity of the usage of OBA is described as that today we are living in an audience era, where everyone and everything has an audience (Global Web Index, 2016). Even though the OBA is widely used by the organizations to do better marketing, reaction to OBA by the customers are not positive all the time. Research and the observations show that customers tend to avoid OBA. There is a global trend of increasing ad block. This is very less in Sri Lanka. But as per the annual ad block report page fair, it shows 16\% of ad block penetration in Asia pacific region (Pagefair, 2017). Therefore, we can see a clear trend based on the stats. The impact of this will mainly affect to mobile advertising. Desktop ad block penetration is only 2\% in Sri Lanka Pagefair predicts that Mobile Ad Block usage is spreading rapidly due to partnerships between ad blocking browsers and device manufacturers \& distributors (Pagefair, 2017; Dencheva, 2009). Therefore, this study attempts to find out why consumers need ad blocking apps and software? Why do they dislike advertisements? Why do they see online ads as an irritating source of communication? The main objective of this study is to find the solutions for online ad avoidance and privacy concern that is highly considerable factor for online consumer behavior.

\section{Literature Review}

Digital platforms are enabling more targeting options for marketers. When the consumers visit or browse the internet the browser save some cookies. By now digital advertising is a well-developed and established advertising medium with enhanced tracking systems and targeting methods. It is easy to track the consumer behavior due to the combination of online platforms with the day today activities of the consumer. Yet, studies say that most of the marketing tactics practiced by companies are irritating to consumers. Pop-ups, Roll-overs, and flashing and noisy advertisements were major examples discussed by the respondents. Even though these ads were able to grab the attention those were perceived as disrupting to the users. The same as the online web pages, social media ad clutter make consumers to think twice when they engage with an online advertisement. (Diffley et al., 2011). Attitudinal studies are another mainstay of the consumer behavior and advertising literature bases (Cummins et al., 2014). As mentioned by Cho et al. (2004), cognition, affect, and behavior are the three elements of consumer attitudinal responses to advertising stimuli, although the order of responses is influenced by other variables, such as involvement. In this study, researchers used all three components of consumer advertising responses in measuring internet ad avoidance. Perceived goal impediment is one of the significant factor that impacts the ad avoidance. Ads lead to aggravation, negative attitudes, and ad avoidance, when they interrupt a consumer's goal (Fan et al., 2017). People use internet to achieve a specific task and they expect to complete their task without any disturbances. Therefore, it can be stated that; the Internet is a goal-oriented medium where users are usually engaged in pursuing specific tasks that can be interrupted by exposure to unsolicited ads, which will make consumers have negative experiences and ads avoidance ( $\mathrm{Li}$ \& Huang, 2016). Hence, it can be hypothesized:

$\mathrm{H}_{1}$ : Goal Impediment is having a significant impact on negative experience.

Privacy can be defined as "the feeling that one has the right to own private information, either personally or collectively" (Petronio, 2002) as cited in (Kim, 2016). The identity we have in digital space is known as digital identity and it encompasses of traceable offline characteristics such as age, residence and income. Digital consumers are no longer anonymous since virtually all the data can be collected related to online consumer behavior based on their online behavior, search queries and social network updates (Eastin et al., 2016). The main reason behind rapidly increasing advertising on social media network is that customers can be targeted by their gender, age, schools/colleges, job title, living and working places, interests, and friends. Therefore, these demographic, geographic, and psychographic information provide personal information where we can target the consumers more precisely by their behavior (Jung, 2017). Hence it can be hypothesized: 
$\mathrm{H}_{2}$ : Privacy concern is having a significant impact on negative experience.

Literature reveals that perceived ad relevance plays an important role in generating significant impact on advertising effectiveness in cognitive, affective, and behavioral areas. It is said that people live to see more relevant ads. Personalized information increases the attention and the elaboration levels on the given contents. Consumers like to see more personalized ads rather than general ads. But they feel little bit uncomfortable with the highly relevant ads (Bang \& Wojdynski, 2016).

$\mathrm{H}_{3}$ : Perceived personalization has a significant impact on negative experience.

Learning from experience theory suggests that people make decisions based on their past personal experiences (Kolb et al., 2001). Thus, consumers' previous experience with an ad can explain their future behavior. Further, affective ad avoidance, involves negative feelings and the expression of emotional reactions toward an advertisement (Seyedghorban et al., 2016; Deshwal, 2016). Researchers such as Cho et al. (2004), Kelly et al. (2010), Kelly (2010), Kelly (2014), and Beak and Morimoto (2012) provide evidences that pervious negative experience has a significant impact on ad avoidance. However when consumers are exposed to hundreds of advertisements per day and this advertising overload may produce negative feelings. People perceive it as advertisements are misleading are an insult the people's intelligence ( Souiden et al., 2017). Therefore previous negative experience with an advertisement may influence on ad avoidance in future (Seyedghorban et al., 2016). Thus the following hypothesis is raised:

$\mathrm{H}_{4}$ : Negative experience has a significant impact on online behavioral ad.

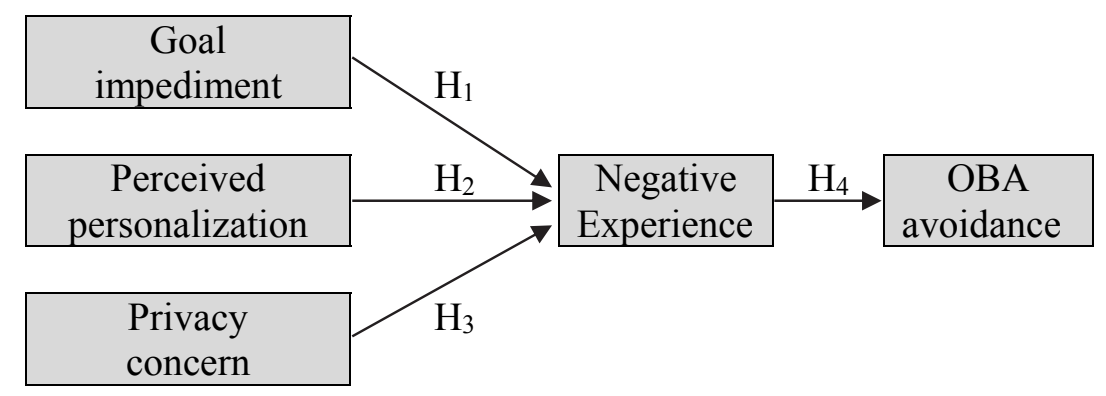

Fig. 1. Conceptual Framework

\section{Methodology/Materials}

\subsection{Data Collection and Sample}

As mentioned above, the conceptual model was established based on a model developed in a previous studies in the area of online behavioral advertising avoidance model (Cho et al., 2004; Kelly, 2014; Seyedghorban et al., 2016; Li \& Huang, 2016; Beak \& Morimoto, 2012). For this study, population was identified as focused age group of male and females within the age group of eighteen to fifty four within Colombo district. Convenient Sampling was used as the sampling technique through which data was collected. Out of the 490 questionnaires distributed, 398 responses were collected. Only 384 questionnaires were usable in the study due to the missing values, incompleteness and other errors. Response rate was $78 \%$ for the study. Based on the literature when the population is more than 1 million and at the confidence level of $95 \%$ they recommend a sample size of 384 (Krejcie \& Morgan, 1970). 
Table 1

Sample Demographics

\begin{tabular}{lll}
\hline & Frequency & Percentage \\
\hline Gender & & \\
Male & 217 & $57 \%$ \\
Female & 167 & $43 \%$ \\
\hline Education & & \\
A/L & 46 & $12 \%$ \\
Undergraduate & 218 & $56.8 \%$ \\
Bachelor's degree/professional qualification & 95 & $24.7 \%$ \\
Postgraduate & 25 & $6.5 \%$ \\
\hline Age & & \\
$18-24$ & 167 & $43 \%$ \\
$25-34$ & 252 & $65.6 \%$ \\
$35-44$ & 122 & $31.8 \%$ \\
\hline $45-54$ & 5 & $1.3 \%$ \\
\hline
\end{tabular}

Table 1 demonstrates the age and education combinations of respondents. The sample has been dominated by undergraduates with $56.8 \%$ and $24.7 \%$ of graduates or equivalent professional qualifications. Around $43 \%$ of the respondents of the sample were between 18 and 24 of age, $65.6 \%$ were between 25 to 34 years, between $35-44$ years' old there were $31.8 \%$ and the rest of the respondents were 45-54 years old. A filtering question was used in the study to find out whether the respondents have seen any kind of online we asked where they have seen any kind of online advertisement. Most of the respondents has seen online ads when they are using Social Networking Sites. (76.9\%). However 64.6\% have seen online ads when searching and browsing, $61 \%$ on YouTube, $52.3 \%$ while using mobile device, $35.4 \%$ in content websites and $30.8 \%$ when checking their emails.

\subsection{Data Analysis Procedures}

To test the model developed for the study path analysis technique was used through AMOS and SPSS. As suggested by Anderson and Gerbing (1988) confirmatory factor analysis (CFA) was used to establish the measurement model. Then a path analysis was performed to test the hypotheses stated in the conceptual model.

Table 2

Discriminant Validity

\begin{tabular}{lllllrr}
\hline & Mean & SD & GI & PC & PP & OAB \\
\hline Goal Impediment (GI) & 2.62 & 0.56 & $\mathbf{0 . 5 6 7}$ & & & \\
Privacy Concern(PC) & 3.01 & 0.83 & 0.367 & $\mathbf{0 . 7 1 1}$ & $\mathbf{0 . 8 1 2}$ \\
Perceived Personalization (PP) & 2.51 & 0.72 & 0.320 & 0.380 & 0.652 & $\mathbf{0 . 7 5 7}$ \\
Negative Experience (NI) & 2.78 & 0.56 & 0.344 & 0.445 & 0.563 \\
Online Add Avoidance Behavior (OAB) & 3.22 & 0.45 & 0.305 & 0.449 & 0.494 \\
\hline Note: Values on the diagonal (italicised) represent the square root of the average variance extracted while the off diagonals are correlations
\end{tabular}

\section{Results and Findings}

\subsection{Measurement Model Analysis}

We used maximum likelihood estimation method to estimate the measurement model of the study. The instrument consisted of 38 items, for the six constructs and the initial CFA was run to test the model fit, convergent validity and discriminant validity (Anderson \& Gerbing, 1988). 13 items with loadings less than 0.5 were removed from the model. The results of the model fit obtained through the CFA are: $(\chi 2=$ $791.211 \mathrm{df} .=260, \mathrm{p}<.01, \chi 2 / \mathrm{df}=3.043$, root mean square error of approximation [RMSEA] $=0.061$ and comparative fit index $[\mathrm{CFI}]=0.901$ ) shows a good fit (Byrne, 1998). To ensure the validity and the reliability of the measurement model, further analysis was conducted where convergent validity and discriminant validity of the model were ensured. Out of the six constructs of the study, the average variance extracted (AVE) is greater than 0.5 for all the constructs (Bagozzi \& Yi, 1988), which confirms the convergent validity of the model (Hair et al., 2014). The CR is greater than 0.7 for all the constructs. 
Table III illustrates the AVE and CR values of all the constructs with the factor loadings. Discriminant validity of the model is assured by comparing the square root of AVE with the correlations between the six constructs (Fornell \& Larcker, 1981). Further, it is observed that the difference between the loadings and the cross loadings shown in Table 2 are all higher than 0.1 which is recommended by Hair et al. (2014). Therefore, it can be concluded that the discriminant validity of the model is confirmed (Hair et al., 2014).

\section{Table 3}

Measurement Model

\begin{tabular}{|c|c|c|c|c|}
\hline Construct & Variables & Loadings & AVE & C.R \\
\hline \multirow[t]{9}{*}{ Goal Impediment(GI) } & $\begin{array}{l}\text { I deliberately ignore targeted online ads when I'm surfing on the } \\
\text { Internet. }\end{array}$ & .532 & 0.588 & 0.906 \\
\hline & $\begin{array}{l}\text { I deliberately ignore targeted online ads when I'm browsing on } \\
\text { the shopping sites. }\end{array}$ & .536 & & \\
\hline & I deliberately ignore targeted online ads when I open my mailbox & .591 & & \\
\hline & Online behavioral ads/Targeted ads are annoyed & .868 & & \\
\hline & Online behavioral ads/Targeted ads make me feel disturbing & .822 & & \\
\hline & Online behavioral ads/Targeted ads are unappealing & .764 & & \\
\hline & If online behavioral ads pop out, I will close them & .792 & & \\
\hline & $\begin{array}{l}\text { I'll take some measures (such as setting the browser) to avoid } \\
\text { online behavioral ads }\end{array}$ & .767 & & \\
\hline & I will remove/unsubscribe online behavioral ads & .745 & & \\
\hline \multirow[t]{6}{*}{ Privacy Concern (PC) } & $\begin{array}{l}\text { It is important for me to know how my personal information is } \\
\text { used }\end{array}$ & .711 & 0.505 & 0.858 \\
\hline & $\begin{array}{l}\text { Online behavioral ads' privacy policies should have a clear ex- } \\
\text { planation }\end{array}$ & .784 & & \\
\hline & $\begin{array}{l}\text { I feel uncomfortable when information is shared without per- } \\
\text { mission }\end{array}$ & .580 & & \\
\hline & $\begin{array}{l}\text { I feel that my privacy is invaded if I can't control my personal } \\
\text { information }\end{array}$ & .821 & & \\
\hline & I'm worried that my record of network activity will be abused & .716 & & \\
\hline & $\begin{array}{l}\text { When the online behavioral ads need my personal information, I } \\
\text { usually will think about for a while. }\end{array}$ & .621 & & \\
\hline \multirow[t]{5}{*}{$\begin{array}{l}\text { Perceived personaliza- } \\
\text { tion }(P P)\end{array}$} & $\begin{array}{l}\text { This personalized advertising makes purchase recommendations } \\
\text { that match my needs }\end{array}$ & .702 & 0.659 & 0.906 \\
\hline & $\begin{array}{l}\text { I think that this personalized advertising on enables me to order } \\
\text { products that are tailor-made for me. }\end{array}$ & .841 & & \\
\hline & Overall, this personalized advertising is tailored to my situation. & .849 & & \\
\hline & $\begin{array}{l}\text { This personalized advertising makes me feel that I am a unique } \\
\text { customer. }\end{array}$ & 0.819 & & \\
\hline & $\begin{array}{l}\text { I believe that this personalized advertising is customized to my } \\
\text { needs. }\end{array}$ & .838 & & \\
\hline \multirow{4}{*}{$\begin{array}{l}\text { Negative Experience } \\
(N I)\end{array}$} & Online behavioral ads are lack of attraction & .785 & 0.574 & 0.843 \\
\hline & Online behavioral ads are lack of usefulness & .772 & & \\
\hline & Online behavioral ads are lack of specificity & .754 & & \\
\hline & Online behavioral ads are lack of incentives & .717 & & \\
\hline \multirow{4}{*}{$\begin{array}{l}\text { Add Avoidance Behavior } \\
(\mathrm{OAB})\end{array}$} & Cognitive Avoidance & .764 & 0.528 & 0.817 \\
\hline & Affective Avoidance & .732 & & \\
\hline & Behavioral Avoidance & .702 & & \\
\hline & Mechanical Avoidance & .708 & & \\
\hline
\end{tabular}

Notes: AVE, average variance extracted; CR, composite reliability. The italicized cells indicate the constructs used

\subsection{Structural Model Analysis}

After validating the measurement model, the structural model was estimated to test the four hypotheses. Fig. 1 shows the path diagram of the study where the four main constructs of the study (Goal Impediment (GI), Privacy Concern (PC), Perceived Personalization (PP), Negative Experience (NI), Add Avoidance $(\mathrm{OAB})$, are shown in rectangles. Arrows between the five main constructs of the study show the hypotheses tested in the study. The results of the model fit of the measurement model are: $(\chi 2=4.328, \mathrm{df} .=1$, $\mathrm{p}<.01, \chi 2 / \mathrm{df}=4.328$, root mean square error of approximation [RMSEA] $=0.048$ and comparative fit index $[\mathrm{CFI}]=0.984)$ revealed that the model fits the data reasonably well. Results of the hypotheses tests are presented in Table IV. The relationship between Goal Impediment and Negative Experience was 
$0.603(\mathrm{p}<.05)$ indicating that Goal Impediment significantly influence Negative Experience, and thus $\mathrm{H}_{1}$ was supported. The hypothesized relationship between Privacy Concern and Negative Experience is significant. The corresponding estimate was $0.234(\mathrm{p}<.05)$ and therefore $\mathrm{H}_{2}$ is supported. The relationship between Perceived Personalization and Negative Experience was $0.456(\mathrm{p}<.05)$ indicating that Perceived Personalization is significantly influence Negative Experience and thus $\mathrm{H}_{3}$ was supported. The relationship between Negative Experience and Add Avoidance Behavior was $0.257(p<.05)$ indicating that Negative Experience significantly influences Add Avoidance Behavior and thus $\mathrm{H}_{4}$ was supported.

\section{Table 4}

Testing the Direct Effects

\begin{tabular}{|c|c|c|c|c|c|}
\hline Hypothesis & Relationship & $\begin{array}{c}\text { Standardized } \\
\text { Coefficients }\end{array}$ & $\mathrm{SE}$ & $\mathrm{P}$ value & Decision \\
\hline H1 & Goal Impediment $\rightarrow$ Negative Experience & 0.603 & 0.111 & 0.025 & Supported \\
\hline $\mathrm{H} 2$ & Privacy Concern $\rightarrow$ Negative Experience & 0.234 & 0.123 & 0.048 & Supported \\
\hline H3 & Perceived Personalization $\rightarrow$ Negative Experience & 0.456 & 0.032 & 0.000 & Supported \\
\hline $\mathrm{H} 4$ & Negative Experience $\rightarrow$ Add Avoidance & 0.257 & 0.139 & 0.020 & Supported \\
\hline
\end{tabular}

\section{Conclusion}

\subsection{Goal Impediment to Negative experience}

In accordance with the literature it's found that coal impediment has a strong positive relationship with the negative experience. ( Li \& Huang, 2016)Based on the literature and the study findings we can say that advertisers should not distract the consumers when they are highly goal oriented. When the advertisement is entertaining consumers are likely to engage more. When the consumers are overloaded with the information in the advertisement they get irritated, therefore goal impediment has a significant impact to the negative experience.

\subsection{Privacy concern to Negative experience}

According to the analysis the relationship between privacy concerns is significant and there is a positive relationship among the variables. By reviewing literature it confirms that there is a positive impact from the negative experience to the privacy concern (Li \& Huang, 2016). This research study also confirms that there is a positive relationship among privacy concern and the negative experience. This is mainly due to the terms and conditions that applied when using online services and cookies. Browsers, websites and online platforms use cookies without permission from the users. Companies should find ways to deliver online ads without interfering to their privacy and irritating when using online platforms (Diffley et al., 2011). Therefore, advertisers can always request permission from the users when collecting cookies, when collecting private information's and advertisers should let the users know on what purpose these data has been collected. But when it comes to Social Networking sites consumers are willingly exposing their personal information's such as age, residence, workplace and social networking sites can collect all the information's that they share and based on their consumer behavior they can identify exactly what type of a consumer is he. Current economies are driven by data or the big data concept is widely addresses by several researchers as wells in the industry. Therefore, as a solution for this transparency with the user is a must. The main ways that consumers perceive that giving or exposing information to an advertiser is that advertisement is target based on their online consumer behavior and the search history. Therefore, consumers feel that they have been tracked and observed by the advertisers. However, based on the literature when the ads are target based on their personal data ad relevance is high which makes the ad more effective.

\subsection{Perceived Personalization to the Negative experience}

Personalization helps to increase the ad relevancy. However, the literature shows perceived personalization is related to negative experience. According to this research study when the perceived personalization increases ad avoidance and the negative experience increases. Which is consumers do not like when 
the ad is more personalized or tailor made for their situation. Based on the literature when the personalization increased ad avoidance should be decreased where consumers are like to receive more personalizes and tailor made ads. (Li \& Huang, 2016). However according to the literature people perceived personalized ads as negative when the ad is highly personalized (Jung, 2017). However, the personalized ads give the negative experience based on the privacy concern.

\subsection{Negative experience with the ad avoidance.}

Since there is a positive significant relationship among variables advertisers should focus on how to reduce the negative experience by increasing the attraction of the advertisement, by giving incentives, and being more useful and specify on the message that want to deliver.

\section{References}

Anderson, J. C., \& Gerbing, D. W. (1988). Structural equation modeling in practice: A review and recommended two-step approach. Psychological bulletin, 103(3), 411.

Bagozzi, R. P., \& Yi, Y. (1988). On the evaluation of structural equation models. Journal of the academy of marketing science, 16(1), 74-94.

Beak, T. H., \& Morimoto, M. (2012). Stay away from me, examining the determinants of individual avoidance of personalized advertising. Journal of Advertising, 41, 59-76.

Bang, H., \& Wojdynski, B. W. (2016). Tracking users' visual attention and responses to personalized advertising based on task cognitive demand. Computers in Human Behavior, 55, 867-876.

Byrne, B. M. (1998). Structural equation modeling with LISREL, PRELIS, and SIMPLIS. London.

Cheng, J. M. S., Blankson, C., Wang, E. S. T., \& Chen, L. S. L. (2009). Consumer attitudes and interactive digital advertising. International Journal of Advertising, 28(3), 501-525.

Chen, Q., Feng, Y., Liu, L., \& Tian, X. (2019). Understanding consumers' reactance of online personalized advertising: A new scheme of rational choice from a perspective of negative effects. International Journal of Information Management, 44, 53-64.

Cho, C. H., \& as-, U. O. T. A. A. I. A. (2004). Why do people avoid advertising on the internet?. Journal of advertising, 33(4), 89-97.

Colombo Digital Marketers. (2017, Feb 23). Colombo Digital Marketers. Retrieved from Colombo Digital Marketers:http://www.digitalmarketer.lk/internet-usage-statistics-in-sri-lanka-2016-updated.html

Cummins, S., W. Peltier, J., A. Schibrowsky, J., \& Nill, A. (2014). Consumer behavior in the online context. Journal of Research in Interactive Marketing, 8(3), 169-202.

Constantinides, E. (2009). Social Media / Web 2.0 as Marketing Parameter: An Introduction.

Dencheva, S. (2009). Effectiveness of Internet advertisement. 3rd Central European Conference in Regional Science - CERS, 2009.

Deshwal, P. (2016). Online advertising and its impact on consumer behavior. International Journal of Applied Research, 2(2), 200-204.

Diffley, S., Kearns, J., Bennett, W., \& Kawalek, P. (2011). Consumer behaviour in social networking Sites: Implications for marketers. Irish Journal of Management, 30(2), 47-65.

Eastin, M. S., Brinson, N. H., Doorey, A., \& Wilcox, G. (2016). Living in a big data world: Predicting mobile commerce activity through privacy concerns. Computers in Human Behavior, 58, 214-220.

Fan, S., Lu, Y., \& Gupta, S. (2017, July). Social Media In-Feed Advertising: the Impacts of Consistency And Sociability On Ad Avoidance. In PACIS (p. 190).

Fornell, C., \& Larcker, D. F. (1981). Structural equation models with unobservable variables and measurement error: Algebra and statistics.

Global Web Index. (2016). The trends to watch in 2017. Retrieved from hello@globalwebindex.net

Google . (n.d.). Generation $Z$ New insights into the mobile-first mindset of teens.

International Advertising Bureau. (2017). IAB NEW STANDARD AD UNIT PORTFOLIO. IAB TECHNOLOGY LABORATORY.

Internet Worl Stats . (2017). June 2017 ASIA INTERNET USE, POPULATION DATA AND FACEBOOK STATISTICS - JUNE 2017. 
Internetlivestats.com. (n.d.). Retrieved from Internetlivestats.com.

Jung, A. R. (2017). The influence of perceived ad relevance on social media advertising: An empirical examination of a mediating role of privacy concern. Computers in Human Behavior, 70, 303-309.

Kelly, L., Kerr, G., \& Drennan, J. (2010). Avoidance of advertising in social networking sites: The teenage perspective. Journal of interactive advertising, 10(2), 16-27.

Kim, H. S. (2016). What drives you to check in on Facebook? Motivations, privacy concerns, and mobile phone involvement for location-based information sharing. Computers in Human Behavior, 54, $397-$ 406.

Li, W., \& Huang, Z. (2016). The research of influence factors of online behavioral advertising avoidance. American Journal of Industrial and Business Management, 6(09), 947.

Li, C. (2016). When does web-based personalization really work? The distinction between actual personalization and perceived personalization. Computers in Human Behavior, 54, 25-33.

Kaushik, k., \& Amrutlal, P. (2014). A Research Paper on Measuring Effectiveness of Online Behavioral Advertisments. International Journal of Scientific Research and Management (IJSRM), 1825-1832.

Kelly, L. (2010). Advertising avoidance in the online social networking environment.

Kelly, L. M. V. (2014). An exploration of advertising engagement, advertising avoidance and privacy concerns on social networking sites (Doctoral dissertation, Queensland University of Technology).

Kelly, L., Kerr, G. F., \& Drennan, J. (2009). 'Try hard': Attitudes to advertising in online social networks. In Proceedings of the Australia and New Zealand Marketing Academy Conference 2009.

Kolb, D. A., Boyatzis, R. E., \& Mainemelis, C. (2001). Experiential learning theory: Previous research and new directions. Perspectives on thinking, learning, and cognitive styles, 1(8), 227-247.

Krejcie, R. V., \& Morgan, D. W. (1970). Determining sample size for research activities. Educational and psychological measurement, 30(3), 607-610.

Pagefair. (2017). The state of the blocked web. PageFair.

Petronio, S. (2002). Boundaries of privacy: Dialectics of disclosure. Albany: State. State University of New York Press.

Seyedghorban, Z., Tahernejad, H., \& Matanda, M. J. (2016). Reinquiry into advertising avoidance on the internet: A conceptual replication and extension. Journal of Advertising, 45(1), 120-129.

Seven Media Group. (n.d.). Retrieved from http://sevenmediagroup.co/social-media-landscape-2017-srilanka/

Seven Media Group. (2017). Seven Media Group. Retrieved from Seven Media Group: http://sevenmediagroup.co/social-media-landscape-2017-sri-lanka/

Souiden, N., Chtourou, S., \& Korai, B. (2017). Consumer attitudes toward online advertising: The moderating role of personality. Journal of Promotion Management, 23(2), 207-227.

Social Bakers . (2017, jan). Retrieved from Social Bakers .

Tene, O., \& Polonetsky, J. (2012). To Track or "Do Not Track": Advancing Transparency and Individual Control in Online Behavioral Advertising. Minnesota Journal of Law, Science \& Technology, 13(1), 281-357.

The Advertising Research Foundation. (2016). Ad Receptivity: A New Metric for Improving Efficiency.

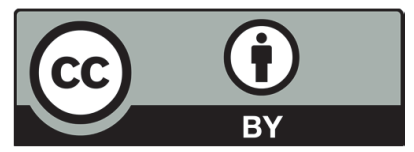

C 2019 by the authors; licensee Growing Science, Canada. This is an open access article distributed under the terms and conditions of the Creative Commons Attribution (CCBY) license (http://creativecommons.org/licenses/by/4.0/). 